\title{
A Critical Approach for Building Teacher Knowledge
}

\author{
Stephanie Chitpin \\ Faculty of Education, University of Ottawa \\ 145 Jean-Jacques Lussier, Ottawa, Canada \\ E-mail: steph.chitpin@uottawa.ca
}

\begin{abstract}
This paper advocates a Popperian approach for empowering teachers to build knowledge when faced with uncertainty or obstacles. It begins with a discussion of the need for schools to use a critical approach for knowledge development and sharing of knowledge. Next, I discuss Popper's three core concepts of critical rationalism to illustrate its relevance in teacher knowledge development, followed by a description of how journal keeping can be situated in Popper's Three Worlds. The paper concludes with a discussion of how Popper's approach can be effective in promoting and sustaining teacher knowledge growth.
\end{abstract}

Keyswords: Critical thinking, critical rationalism, knowledge development, Popper, teacher development 


\section{Introduction}

'Critical thinking' and 'lifelong learning' are words that appear frequently in educational reform literature (Mason, 2008). Much of this literature concludes that if we want our teachers to produce active, creative and critical thinking learners, they need to guard themselves against case building where they selectively seek evidence to support their teaching methods despite evidence pointing to the contrary (Bailin \& Siegel, 2003; Lam, 2008 ). They need to evaluate critically the proposed curriculum activities and to also be able to articulate their reasoned decision to adopt or adapt these curriculum activities to meet the learning needs of their students. In other words, teachers need to become aware of confirmation biases that appear in various guises so they can be more open to opinions that differ from their own.

Like all humans, we have a natural tendency to look for instances that confirm our story and our vision of the world. These instances are always easy to find because we take past instances that corroborate our theories and we treat them as evidence (Baron, 1995; Lam, 2008; Nickerson, 1998; Pyszczynski \& Greenberg, 1987). This is particularly relevant when it comes to professional knowledge development (Chitpin, Simon \& Galipeau, 2008; Chitpin \& Evers, 2005). For example, teachers use the success of their strategies, or "tricks of the trade" to imply that the theory behind it is valid. The fact that the strategies they have used in a particular situation have turned out to be successful proves very little, if anything. One cannot infer much from a single experiment in a random context simply because an experiment needs a repeatability showing some causal component (Popper, 1980). There is also the difference between what teachers actually know and how much they think they know. They certainly know a lot, but they do not know what they do not know (Lam, 2008; Taleb, 2005). For example, "tricks of the trade" can be repeatedly successful over time, thereby confirming, as a result of successful usage, that the practice works, even if based on faulty theories, that is doing the right things for the wrong reasons. Lack of knowledge about the quality of their knowledge comes together - the same process that makes them know less also makes them satisfied with their knowledge (Matlin \& Stang, 1978; Polya, 1954). For example, much empirical evidence supports the view that people have a tendency to demand less hypothesis-consistent evidence for accepting a hypothesis than hypothesis-inconsistent information for rejecting a hypothesis (Baron, 1995; Nickerson, 1998; Pyszcynski \& Greenberg, 1987; Lam, 2008).

Furthermore confirmation bias and belief perseverance are at play. This is because we tend to treat ideas like possessions, and it is hard for us to part with them. When testing a hypothesis, we tend to look for instances where the hypothesis proved true (Henrion \& Fischhoff, 1986; Tweney, 1989). However, it is misleading to build general rule from observed facts (Popper, 1989). Contrary to conventional wisdom, our body of knowledge does not grow from a series of confirmatory observations (Dawson, Gilovich, \& Regan, 2002; Lam, 2008). In fact, Popper (2002) argued that knowledge does not progress from tools designed to verify or help theories, but rather the opposite. In the Chitpin et al. (2009) study on the use of the Objective Knowledge Growth Framework found that the Popperian framework helped teachers to refute their confirmation biases thereby enabling them to develop the habit of reflection, thus 
contributing to knowledge growth. As well, because of our inability to predict future course of history, not because of our inability to predict the future growth of human knowledge, but as Popper (2002) put it: 'if there is such a thing as growing human knowledge, then we cannot anticipate today what we shall know only tomorrow' (p. xii). In this paper, I advocate a Popperian approach for empowering teachers to build knowledge when faced with uncertainty or obstacles. I begin with a discussion of the need for schools to use a critical approach for knowledge development and sharing of knowledge. Next, I discuss Popper's three core concepts of critical rationalism to illustrate its relevance in teacher knowledge development, followed by a description of how journal keeping can be situated in Popper's Three Worlds (Chitpin, 2006; Chitpin \& Evers, 2005). I conclude with a discussion of how Popper's (1979) approach can be effective in promoting and sustaining teacher knowledge growth.

\section{Using a Critical Approach for Teacher Development}

Fullan (2006) argues that schools need to focus on knowledge growth and sharing if teaching is to be seen as an intellectual profession; that principals need to understand the role of knowledge development in the performance of their schools. Fullan argues that the role of the principals in promoting knowledge growth is through teacher professional development. He suggests that despite structural constraints, teachers need mechanisms to actively collaborate and share with colleagues ideas, teaching strategies and identification and resolution of problems encountered in their teaching contexts in order to construct professional knowledge.

Information is not synonymous with knowledge. In fact, Brown and Duguid (2000) argue that information is mechanistic and technical whereas knowledge is inherently people oriented. By sharing perspectives and reasons with colleagues, a superior performance is achieved and this performance is attributed to collaborative reasoning rather than to peer pressure or imitation (Moshman \& Geil, 1998; Lam, 2008). Therefore, for teachers to create knowledge they need to assess their underlying assumptions and evaluate their beliefs and actions in a socially processed environment. Such an environment is created when, “...we digest rather than merely hold. It entails the knower's understanding and some degree of commitment” (Brown and Duguid, 2000, p.120). For this reason, mandating teachers to attend professional workshops or external training has not always been highly productive. Rather, principals need to provide teachers with environments and settings where they feel safe in sharing their experiments, their successes and their mistakes (Brookfield, 1995). Brookfield further states: new possibilities for our practice and new ways to analyze and respond to problems. Colleagues can open up unfamiliar avenues for inquiry, and they can give us advice on how they deal with the problems they are facing (p. 141).

Rooney (2007) and Loughran (2006) state that student success depends on the expertise of teachers, which in turn depends on the quality of their professional development. Because of funding restraints, schools are finding it harder to provide teachers with opportunities for professional development (Rooney, 2008). If student learning is to improve then teachers must be supported through time and money to create a culture where they continuously 
develop themselves as professionals (Chitpin \& Knowles, 2009). Popper's critical approach can be powerful in helping teachers to critically examine their teaching practice and to refine their theory and practice. This kind of examining or thinking can be practiced both autonomously and in a collegial and collaborative manner. In fact, studies have shown beneficial effects of peer interactions in solving problems of practice (Moshman and Geil, 1998; Butraa, Caverni and Rossi, 2005). By engaging in critical conversations, teachers are making visible the inadequacies of their teaching practices so as to effect changes that eliminate or minimize those adequacies (Fugelsang et al., 2004; Lam, 2008). This also prevents them from prematurely accepting theories or solutions that may be spurious while allowing them to revise their theories for building knowledge.

\section{Popper's Three Core Concepts of Critical Rationalism}

Popper's (1966) philosophy of 'critical rationalism' can be understood, in Popper's own words, as admitting that, 'I may be wrong and you may be right', and that 'by an effort, we may get nearer to the truth' (p. 225). This effort which he has in mind is the effort of critical discussion. It is an effort by which we discover a problem, propose a theory as a tentative solution, implement the theory to eliminate errors that we find in it, and by eliminating those errors we progress to the discovery of a new problem. His three core concepts of critical rationalism are fallibilism, criticism and verisimilitude.

Popper's (1966) fallibilism views human beings and their scientific knowledge as inherently fallible and subject to error. Although his idea was quite controversial in the 1930s when Popper published his Logik der Forschung (Popper, 1934), his idea is now well accepted by most contemporary philosophers of science even though it is not the most distinctive feature of Popper's epistemology. He argued that what was once substantiated historically by fact may later turn out to be false. He stated furthermore that the very best of our scientific knowledge is fallible because we cannot 'justify' our theories by showing that they are actually true. In addition, there is also the limitation of our ability to predict the future course of history, not because of our inability to predict the future growth of human knowledge, but because, as Popper (2002) puts it, “...If there is such a thing as growing human knowledge, then we cannot anticipate today what we shall know only tomorrow” (p.xii). Thus, his fallibilism disregards certain knowledge and, more specifically, authoritative sources of knowledge. Instead, he argues that nothing is secure and that our knowledge is conjectural and fallible.

Since we learn from our mistakes, fallibilism should not lead to skeptical or relativist conclusions. Popper (1966) claims that criticism “...is the only way we have of detecting our mistakes, and of learning from them in a systematic way” (p. 376). Criticism includes criticizing the theories or conjectures of others and of our own because, for Popper (1989), criticism consists of deductive logical reasoning to remove inconsistencies from our theories, modify or refine or replace our theories when they do not do what they are intended to do or when contradictions occur. In other words, the application of deductive or formal logic to criticism adopts the rules by which truth is transmitted from premises to conclusions, whereas falsity is re-transmitted from conclusions to premises. This re-transmission of falsity is also 
called refutation. In fact, Popper (1989) rejected all attempts to justification of theories; instead he replaced justification with criticism in his non-justificationist or falsificationist view of rationality. Because a theory may stand up to criticism better than its competitors, Popper stated that we can sometime 'justify' our preference for a theory in the negative sense if the theory finds some kind of support instead of securing positive evidence without being subjected to severe criticism.

Crucial to Popper's (1979) concept of critical rationalism is the concept of verisimilitude (getting closer to the truth) because it is only the idea of the truth that allows us to speak sensibly of fallibilism and criticism. In other words, it is through searching and eliminating mistakes through critical discussions that we can come nearer to the truth. Popper (1989) adopted Tarski's (1936) correspondence theory of objective truth that a statement is true only when it corresponds to the facts. Although Tarski's objective theory of truth allows us to make certain assertions and appears correct to Popper, his theory is self-contradictory within the subjective theories of truth, for example a theory may be true even though no-one believes it and when there is no reason to believe that it is true. Conversely, another theory may be false even when we have reason to accept it. In our search for truth, we may never know when we have found it because we have no criterion of truth but are guided only by the idea of truth as a regulative principle. To alleviate suspicion about the idea of getting closer to the truth, Popper (1979) introduced a logical idea of verisimilitude by combining truth and content. He defined all true statements and false statements following from a statement $p$ as the truth content and falsity content of $p$ respectively. He explained it as follows:

Intuitively speaking, a theory $\mathrm{T}$, has less verisimilitude than a theory $\mathrm{T} 2$ if and only if (a) their truth contents and falsity contents (or their measures) are comparable, and either (b) the truth content, but not the falsity content, of T1 is smaller than that of T2, or else (c) the truth content of $\mathrm{T} 1$ is not greater than that of $\mathrm{T} 2$, but its falsity content is greater (p. $52)$.

Thus, he regarded the search for verisimilitude rather than truth as a more realistic aim of science because while we cannot have sufficiently good arguments for claiming that we have attained the truth, we can have good arguments for claiming that we have made progress towards the truth. In other words, T2 is epistemically more progressive than its predecessor T1 and therefore it is preferred. In asking whether the critical rationalism approach can promote teacher knowledge growth, it is a good idea to start with a discussion of Popper's (1979) Three Worlds and its implications for teacher knowledge growth.

\section{Popper's Three Worlds}

According to Popper (1979), individuals engage with their surroundings on three levels. The first is the physical world or the world of physical states (World 1); the second is the mental world or the world of mental states (World 2); and the third world is the world of ideas in the objective sense (World 3). World 3 is a world of possible objects of thought: the world of theories in themselves, and their logical relations; of arguments in themselves; and of problem situations in themselves. 
The three Worlds are so interrelated that the first two can interact and the last two can interact. We can say that the second world, which is the world of subjective or personal experiences, interacts with each of the other two Worlds. The first and third Worlds cannot interact; they can only do so through the intervention of the second World, the world of subjective or personal experiences. In other words, the second World acts as a mediator between the first and the third. For example, Journal keeping can be used to promote teachers' knowledge growth, teachers' minds can see a physical body, the physical journal, in the literal sense of 'see' in which the eyes participate in the process (See Chitpin et al., 2006). Although 'see' is used in a metaphorical way, it nevertheless denotes a real relationship between the mind of the teacher and its intelligible object, the journal. Thus a teacher's mind (World 2) may be linked with objects of both the first World (physical journal) and the third World (the ideas contained in the journal). A teacher's thinking establishes an indirect link between the first and the third World.

This theoretical framework may be regarded as a measure for teachers' professional growth and development of professional knowledge because it acknowledges the subjective intellectual world of teachers' teaching experiences, (which is one of the main functions of the second World), enabling access to the objects of the third World. This is important because it is an essential part of all human learning that to learn is to grasp objective thought contents or senses as Frege (1879) called them.

Furthermore, human language belongs to all three Worlds; therefore, teachers' articulated teaching experience belongs to all three worlds. Where teachers' experience is contained in a physical object, such as the Journal, it belongs to the first World. Where the experience expresses a subjective or psychological state, it belongs to the second World. Where the experiences articulated by teachers are expressed in language which contains information or conveys meaning, it belongs to World three. Theories remain the most important third World linguistic entities (Popper, 1979).

Popper (1979) adopts the view that the third World (part of which is human language) is the product of human creation. Because human language belongs to the larger parts of the third World, they are unplanned products of human actions, which may or may not be solutions to other problems. Some scholars may argue that journals belong in World 2 (Bereiter, 2002; Lakoff, 1987; Lakoff \& Johnson, 1980). However, in this study, I suggest that journals also have a place in World 3 since teachers' reflection, a psychological World two process, can conform to Popper's schema which is about World 3 objects.

This World 2 process also has as its ultimate aim the advancement of teacher and student learning; World 3 can refer to the world of teaching recipes (like cooking recipes) that are being created, tested, discussed, and modified by teachers, while World 2 can refer to teachers' views that mediate the other two worlds. Instead of storing all the rules pertaining to a concept of a subject matter and other relevant cognitive and emotional feelings in teachers' minds, teachers can prevail by using journals as an extension of the mind, as a way of storing and even manipulating information "off-line" as it were. 
In understanding the role of the journals for the growth of teachers' knowledge, it is interesting to see that unexpected new problems arise as an unintended by-product of the process of solving other problems; for example, one teacher, Kris, found that in teaching her students to gain an appreciation of literacy and its components, she first needed to introduce them to three related concepts of literacy, shared and guided reading as well as critical literacy. As Popper (1979) has suggested, these problems are autonomous. Even though these problems are not created by teachers, these problems still exist and need to be solved by teachers. In a teacher's attempts to solve problems, for example, of how to teach students in order to gain an appreciation of literacy and its components, new theories (theory-in-use) are invented. These new theories are produced by teachers; they are the product of teachers' critical and creative thinking, in which they are greatly helped by other existing third World theories. The moment teachers have produced these theories, they discover new, unintended and unexpected problems - autonomous problems.

The growth of the problems results from a kind of feedback effect. Many of these problems may not always be mastered and there will always be the challenging task of discovering new problems, for an infinity of problems will always remain undiscovered. Because of that, and because of the autonomy of the third World, there will always be scope for original and creative work; that is, for authenticity (Popper, 1979).

In the case of teachers' professional knowledge, teachers' interpretations of an outcome or activity are regarded as a theory. For instance, teachers provide explanations that are supported by a chain of arguments and teaching material. Therefore, when teachers make interpretations, these can be regarded as a kind of theory and, like every theory, they are anchored in other theories, and in other third World objects. In this way, the third World problem of the merits of the interpretation can be raised and discussed, including, and especially, its value for our historical understanding (Chitpin, 2003; Chitpin, 2006).

The process or activity of understanding consists, essentially, of a sequence of states of understanding. It is the sequence of the preceding states that constitutes the process, and it is the work of criticizing the state reached (that is, of producing third World critical arguments) that constitutes the activity (Chitpin, 2003). Popper (1979) represents the activity by a general schema of problem solving by the method of conjecture and refutation. The schema is:

$$
\mathrm{P} 1 \rightarrow \mathrm{TT} \rightarrow \mathrm{EE} \rightarrow \mathrm{P} 2
$$

Here P1 is the problem from where teachers start, TT (the tentative theory) is the imaginative conjectural solution which teachers first come up with; for example, the teachers' "interpretations" first tentative interpretation. EE (error elimination) consists of a critical examination of the teachers' conjectures, and their tentative interpretations: it consists, for example of the critical use of teaching material and, if they have at this early stage more than one conjecture at their disposal, it will also consist of a critical discussion and comparative evaluation of the competing conjectures. P2 is the problem situation as it emerges from their first critical attempt, and so on. A satisfactory understanding will be reached if the interpretation, the tentative theory, finds support in the fact that it can shed light on new problems or more problems than teachers expected; or if it finds support in the 
fact that it explains many sub-problems, some of which were not seen at the beginning. Teachers can gauge the progress they have made by comparing P1 with some of their later problems, identified, for example, as Pn. This schema is widely applicable, operates entirely on the third World objects as problems, conjectures and critical arguments, and yet is an analysis of what teachers are doing in their subjective second World that they are trying to understand. For example in a teacher's attempt to become a more effective math teacher (P1), Martha wanted to use the constructivist 'hands-on' approach in her math lessons, (TT1). She discovered after reading on the constructivist approach that her learning style is that of, "I need to read, hear and see in order to best understand" (EE1). She attended a hands-on math workshop and arrived at a new problem: 'How to apply/adapt this hands-on approach to teaching math’ as (P2).

\section{Understanding and Problem Solving}

The activity of understanding is the same as that for all problem solving. Like all intellectual activities, it consists of subjective second World processes (Popper, 1979). Yet, the subjective work involved can be analyzed, as an operation with objective third World objects. If teachers are interested in the process of understanding their own professional growth, or in some of its results, they have to describe what they are doing, or achieving, almost entirely in terms of these objects of understanding, the intelligibles, and their relationships (Chitpin, 2003). When teachers use a journal, Bridgman (1951) calls a 'paper and pencil operation', they must first ask: "What was the problem?" And in order to eliminate the error, they reflect on the activity with a pencil and paper. Though teachers start from dealing with an underlying problem (P1); they proceed from there to a proposition or tentative theory (TT1); and later to a method of implementing the changes designed to eliminate errors (EE1). The second problem (P2) comes in. This method of error elimination leads to a new problem (P2).

Popper's (1979) epistemology can be labelled as 'conjecturalism' as he argues that all scientific knowledge is conjectural. He advocates that we adopt a rational attitude which recognizes the limits of our knowledge and the need for the 'trial and error elimination' method. His epistemology of the three Worlds is thus relevant to the problem of knowledge growth in all its dimensions. The framework is also a powerful tool for carrying an entire suite of ideas. It enables teachers to ask more penetrating questions and obtain answers on important educational questions to enrich the inquiry process. For example, the framework helps generate information as to how a physical journal can interact with a set of ideas and the contents of teachers' professional consciousness, expressed in the journal, allows teachers to expand their capacity to solve problems, deal with classroom situations and behave appropriately in both simple and complex situations. Through elimination of errors in solving daily problems such as classroom management, teachers are led to the objective growth of knowledge. The learning process is not a repetitive one but rather it is a cumulative process driven by error-elimination (Chitpin et al, 2008). Teachers' knowledge growth would thus appear to fit the following Popperian schema:

$$
\mathrm{P} 1 \rightarrow \mathrm{TT} \rightarrow \mathrm{EE} \rightarrow \mathrm{P} 2
$$

The framework helps generate information for readers as to how teachers make use of their 
journal for knowledge growth. It also answers questions in relation to ways in which knowledge growth takes place when teachers adopt the practice of writing in their journal solutions, tips, notes, shortcuts for solving simple and complex problems. Therefore, the journal contains an important set of World 3 ideas that are part of a teacher's wider World 3 professional knowledge and it plays a major role in contributing to teacher knowledge growth by being located in the: $\mathrm{P} 1 \rightarrow \mathrm{TT} \rightarrow \mathrm{EE} \rightarrow \mathrm{P} 2$ growth cycle.

In Popper's (1979) paper Epistemology without a knowing subject, he claims that World 2 can contribute almost nothing worthwhile to the reader's understanding of World 3 and that World 3 is vastly important for understanding World 2. However, Evers (2000) suggests that the human brain, which is a vastly successful learning engine, permits the growth of knowledge using a more complex process that involves the role of coherence. In other words, he argues that Popper's formula $\mathrm{P} 1 \rightarrow \mathrm{TT} \rightarrow \mathrm{EE} \rightarrow \mathrm{P} 2$ needs to take into consideration ways in which teachers make coherent adjustments to their tentative theory in the process of error elimination. Evers further suggests that in accounting for the role of journal keeping in promoting teachers' professional growth and development, teachers need to attend to the World 3 features of professional knowledge, the link between the World 1 portfolio and its use by cognizing agents in being appropriated into a World 2 portfolio. This World 2 journal belongs to the world of psychology. This has implications for contributing to the professional growth and development of World 3 professional knowledge which, according to Popper (1979), is anti-psychological in orientation.

Using Popper's three Worlds, a journal can be viewed in three ways. World 1 is physical, a notebook, while World 2 is a way to classify a subset of teachers' professional consciousness that has to do with teachers' values. World 3 is a set of ideas, the contents of teachers' professional consciousness or the sense expressed by the physical artifacts such as words and diagrams, that is called professional knowledge.

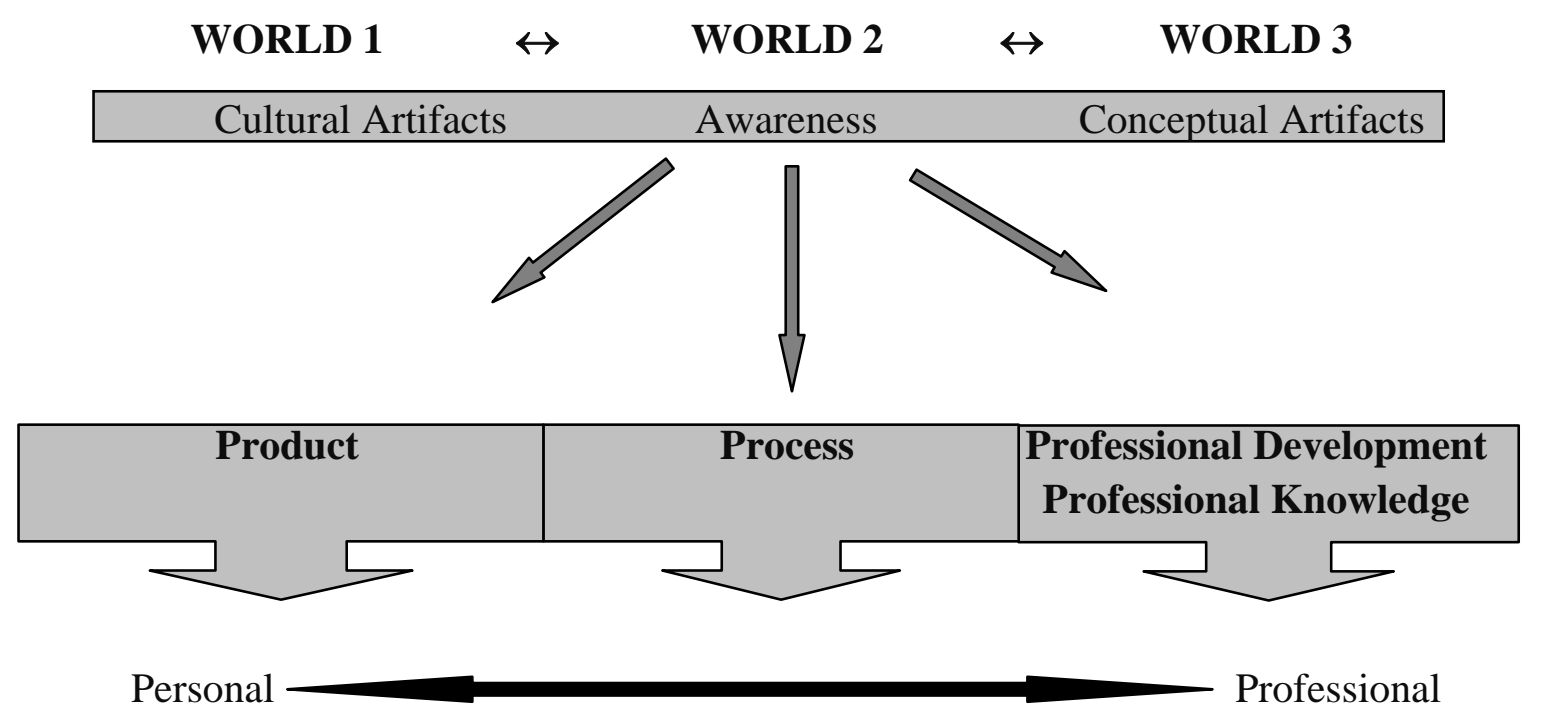

Figure 1. Reconceptualization of Popper's (1979) View of Three Worlds.

In Figure 1, the cultural artifacts belong to World 1, while conscious awareness expressed by 
the teachers' in their journals belongs to World 2 and the conceptual artifacts such as the ideas or contents of the teachers' journals belong to World 3. Teachers' journals can be product or process oriented and, as such, can be situated on a continuum of professional to personal. Product or process orientations can exist in all three Worlds. That is to say, journals can be used conceptually for the development of the professional knowledge realm.

\section{Is Popper's Critical Approach Effective in Building Teacher Knowledge?}

Despite Popper's influence in the philosophy and practice of science, the question still remains of the effectiveness of his methodology for solving problems. There is controversy in the psychology literature over the feasibility and utility of falsification as a strategy for solving problems. Literature on psychological studies suggests that scientists have difficulty in disconfirmatory reasoning (Mahoney \& Kimper, 1976; Einhorn \& Hogarth, 1978). However, Tweney et al. (1980) attempted to teach their participants disconfirmatory strategies using the 2-4-6 problems. The results of their study reveal success in eliminating most attempts at confirmation and in changing the inquiry strategy of participants in the disconfirmatory group. Thus, their study shows that it is feasible to induce the use of disconfirmation.

Confirmation bias can partially be attributed to the fact that people have the tendency to consider only one hypothesis at a time. In fact, Tweney et al. (1980) found that individuals seldom employ this thinking strategy successfully because they prefer 'to evaluate several pieces of data against a single hypothesis, rather than one datum against several hypotheses' (p. 119). Through Popper's (1979) schema, teachers can be encouraged to think of several alternative hypotheses simultaneously in attempting to solve a problem of practice. For example several teachers teaching similar grades can work on different hypotheses to solve a classroom related problem. This is further illustrated in Chitpin and Simon (2006), where Emily and Vanessa, two pre-school teachers attempted to solve their problem of teaching sequencing to their kindergarten students using different theories. Emily chose to read the story If you give a mouse a cookie to explore the meaning of the word, sequencing, (TT1) whereas Vanessa's tentative solution (TT1) is to get her students to make predictions and to notice the sequence of the story The very hungry caterpillar. Through students' feedback, both Vanessa and Emily discovered that their students did not grasp the concept of sequencing (EE1). As a result, they both refined their initial problem of introducing the concept of sequencing to "How to improve students understanding of sequencing"? (P2) (See Table 1). Evers (2008) argued that regardless of background and teaching experiences there are common constraints in problems and in reaching solutions for these problems. Nickels (1981) defined it:

My short answer is that a problem consists of all the conditions or constraints on the solution plus the demand that the solution (an object satisfying the constraints) can be found. For this reason..., I call it the constraint-inclusion model of problems. The constraints characterize - in the sense 'describe' - the sought-for solution (p. 109).

There are different ways of solving a problem within a given constraint. However, regardless of background or the number of teaching experiences, Popper's (1979) schema provides participants with a tool to solve problems that their own system of priorities says is worth 
solving. In other words, the schema provides participants with a framework that respects the priorities that define the problem (Chitpin \& Evers, 2005; Chitpin, 2006; Chitpin \& al, 2008). Given that we bring an enormous amount of background knowledge to solve a given problem, the number of constraints will no doubt be large. However, we must find ways to frame our problems and solutions so that this background knowledge will not interfere with the cognitive processing (Dietrich \& Fields, 1996; Evers, 2008). In fact, if we effectively bracket much of the background and focus on one or two aspects of the problematic situation, we can often make epistemic progress in solving the problem. This is further illustrated using the examples of Vanessa and Emily in solving their problem of teaching sequencing to their pre-schoolers (see Chitpin \& Simon, 2006). Emily and Vanessa's initial problem was: How to teach students sequencing? For this problem, they each formulated an initial tentative theory (TT1) as a hypothesis, with everything else assumed as background. They then put their theory to the test to eliminate errors or weaknesses emerged from the test (EE1). Popper's (1979) schema repeats with a new problem as a result of addressing the errors in the initial problem. As illustrated in Table 1, there is no guarantee that knowledge growth will end at a particular point. In fact, Vanessa's initial problem, that of teaching students sequencing, ended with 'how to teach students to find the missing number on the line'. However, there is evidence that there are gains in Vanessa's knowledge as depicted in the Table below.

\section{Conclusion}

To sum up, I have argued that knowledge building or knowledge growth requires a critical approach. Using Popper's critical rationalism approach as a professional development tool exposes teachers to the concept of thinking of several alternative hypotheses simultaneously in seeking an explanation of a phenomenon. It also encourages them to assess, individually or collectively, evidence objectively in the formation and evaluation of their theories, not to mention that it prompts them to look at inconsistent data with a critical attitude. I have argued that it is through criticism and through making visible what is wrong that errors or inadequacies can be eliminated or minimized. Mandating teachers to attend workshops or enlisting them as consultants to provide workshops are not highly effective. The role of the principal is to provide teachers with an environment where the latter can look for critical dialogue with others involved in the educational enterprise so as to find ways to eliminate the inadequacies of their teaching practice. This critical approach places the responsibility for improvement on the teachers. Furthermore, it educates teachers to be more receptive when colleagues point out the inadequacies of whatever they fail to approach critically. The critical approach is not only a way for teachers to build or grow knowledge but is also a way for teachers to maximize student success.

\section{References}

Baron, J. (1995). Myside Bias in Thinking about Abortion. Thinking and Reasoning, 7, (221-235).

Bereiter, C. (2002). Education and Mind in the Knowledge Age. Lawrence Erlbaum Associates, Inc. Mahwah, NJ.

Bridgman, P. W. (1951). The nature of some of our physical concept. The British Journal for 
Philosophy of Science, II (5): 25-44.

Brookfield, S. D. (1995). Becoming a Critically Reflective Teacher. San Francisco: Jossey-Bass Publishers.

Brown, J. S., \& Duguid, P. (2000). The social life of information. Boston: MA, Harvard Business Books Press.

Butera, F., Caverni, J. P., \& Rossi, S. (2005). Interaction with a high-versus low competence influence source in inductive reasoning, The Journal of Social Psychology, 145, 173-190.

Chitpin, S., \& Knowles, J. G. (2009). A principal's view on the use of the Objective Knowledge Growth Framework (OKGF) as a reflection tool, In. M. P. Caltone, Handbook of Lifelong Learning Developments, New York, NY, Nova Science Publishers, Inc. Ch. 12, pp.1-15.

Chitpin, S., \& Simon, M. (2006). Exploring the Popperian Framework in a Pre-Service Teacher Education Program. Teaching Education, 17(3), 355-369.

Chitpin, S. (2003). The role of portfolios in teachers' professional growth and development: A knowledge building analysis. Unpublished Doctoral Dissertation, University of Toronto, Toronto, Canada.

Chitpin, S., \& Evers, C. W. (2005). The role of professional portfolios for teachers.

Chitpin, S., Simon, M., \& Galipeau, J. (2008). Pre-service teachers' use of the Objective Knowledge Growth Framework for reflection during practicum. Teaching and Teacher Education, 24(8), 2049-2058.

Dawson, E., Gilovich, T., \& Regan, D. T. (2002). Motivated Reasoning and Performance on the Wason Selection Task. Personality and Social Psychology Bulletin, 28, 1379-1387.

Dietrich, E., \& Fields, C. (1996). The Role of the Frame Problem in Fodor's Modularity Thesis: A case study of rationalist cognitive science, In K. Ford \& Z. W. Pylyshyn (eds), The Robot's Dilemma Revisited: The frame problem in artificial intelligence. Norwood, NJ, Albex, pp. 9-24.

Einhorn, H. J., \& Hogarth, R. M. (1978). Confidence in judgment: Persistence of the illusion of validity, Psychological Review, 85, 395-416.

Evers, C.W. (2008). Culture, cognitive Pluralism and Rationality, In M. Mason, Critical Thinking and Learning, Oxford, Oxford, Blackwell Publishing, pp. 25-43.

Frege, D. (1879). Conceptual notation, and related articles. Oxford, UK: Clarendon Press.

Fullan, M. (2006). The future of educational change: System thinkers in action. Journal of Educational Change, 7(1), 113-124.

Henrion, M., \& Fischhoff, B. (1986). Assessing Uncertainty in Physcial Constants. American Journal of Physics, 54, 791-798.

Lakoff, G. (1987). Women, fire, and dangerous things: What categories reveal about the mind. Chicago, IL: University of Chicago Press.

Lakoff, G., \& Johnson, M.(1980). Metaphors we live by. Chicago: University of Chicago Press.

Lam, S. M. (2008). Is Popper's Falsificationist Heuristic a helpful resource for developing critical thinking? In M. Mason, Critical Thinking and Learning, Oxford, Oxford, Blackwell 
Publishing, pp. 93-108.

Loughran, J. (2006). Developing a pedagogy of teacher education: Understanding teaching and learning about teaching. Routledge. Taylor \& Francis Group. London.

Mahoney, M.J., \& Kimper, T. P. (1976). From Ethics to Logics: A survey of scientists, In M.J. Mahoney, Scientist as Subject: The psychological imperative, Cambridge, MA, Ballinger Publishing Company, pp. 187-193.

Mason, M. (2008). Critical Thinking and Learning. In M. Mason, Critical Thinking and Learning, Oxford, Oxford, Blackwell Publishing, pp. 1-11.

Matlin, M. W., \& Stang, D. J. (1978). The Pollyanna Principle: Selectivity in language, memory and thought. Cambridge, MA, Shenkman.

Moshman, D., \& Geil, M. (1998). Collaborative reasoning: Evidence for collective rationality. Thinking and Reasoning, 4, 231-248.

Nickels, T. (1981). What is a problem that we may solve it? Synthese, 47, 45-118.

Nickerson, R.S. (1998). Confirmation Bias; A ubiquitous phenomenon in many guises. Review of General Psychology, 2, 175-220.

Polya, G. 91954). Mathematics and Plausible Reasoning: Induction and analogy in mathematics, vol.1. Princeton, NJ, Princeton University Press.

Popper, K. R. (1966). The Open Society and Its Enemies: The high tide of prophecy, $5^{\text {th }}$ edn. Vol. 2, London, Routledge.

Popper, K. R. (1979). Objective Knowledge: An evolutionary approach. Oxford, Oxford University Press.

Popper, K. R. (1980). The Logic of Scientific Discovery, $4^{\text {th }}$ edn. London, Unwin Hyman, Ltd. Popper, K. R. (1989). Conjectures and Refutations: The growth of scientific knowledge, $5^{\text {th }}$ edn. London, Routledge.

Popper, K. R. (2002). Unended Quest: An intellectual autobiography, $2^{\text {nd }}$ edn. London, Routledge.

Pyszczynski, T., \& Greenberg, J. (1987). Toward an integration of cognitive and motivational perspectives on social inference: A biased hypothesis-testing model. In L. Berkowitz (ed.), Advances in Experimental Social Psychology, vol. 20. New York Academic Press, pp297-340.

Rooney, J. (2007). Who Owns Teacher Growth? Educational Leadership. April, 87-88.

Rooney, J. (2008). Taking Hold of Learning. Educational Leadership. November, 82-83.

Taleb, N. M. (2005). Fooled by Randomness: The Hidden role of chances in life and in the markets. New York, Random House Trade paperback Edition.

Tarski, A. (1936). The Concept of Truth in Formalised Languages. In Encyclopedia Britannica. Retrieved December 06, 2009, from Encyclopedia Britannica [Online] Available: http://www.britannica.com/EBchecked/topic/130987/

Teachers and Teaching: Theory and Practice, 11(4), 419-433.

Tweney, R. D., Doherty, M. E., Worner, W. J., Pliske, D.B., Mynatt, C.R., Gross, K.A., \& Arkkelin, D.L. (1980). Strategies of rule discovery in an ingerence task, The Quarterly 


\section{Macrothink}

Journal of Experimental Psychology, 12, 129-140.

Table 1. Knowledge Building

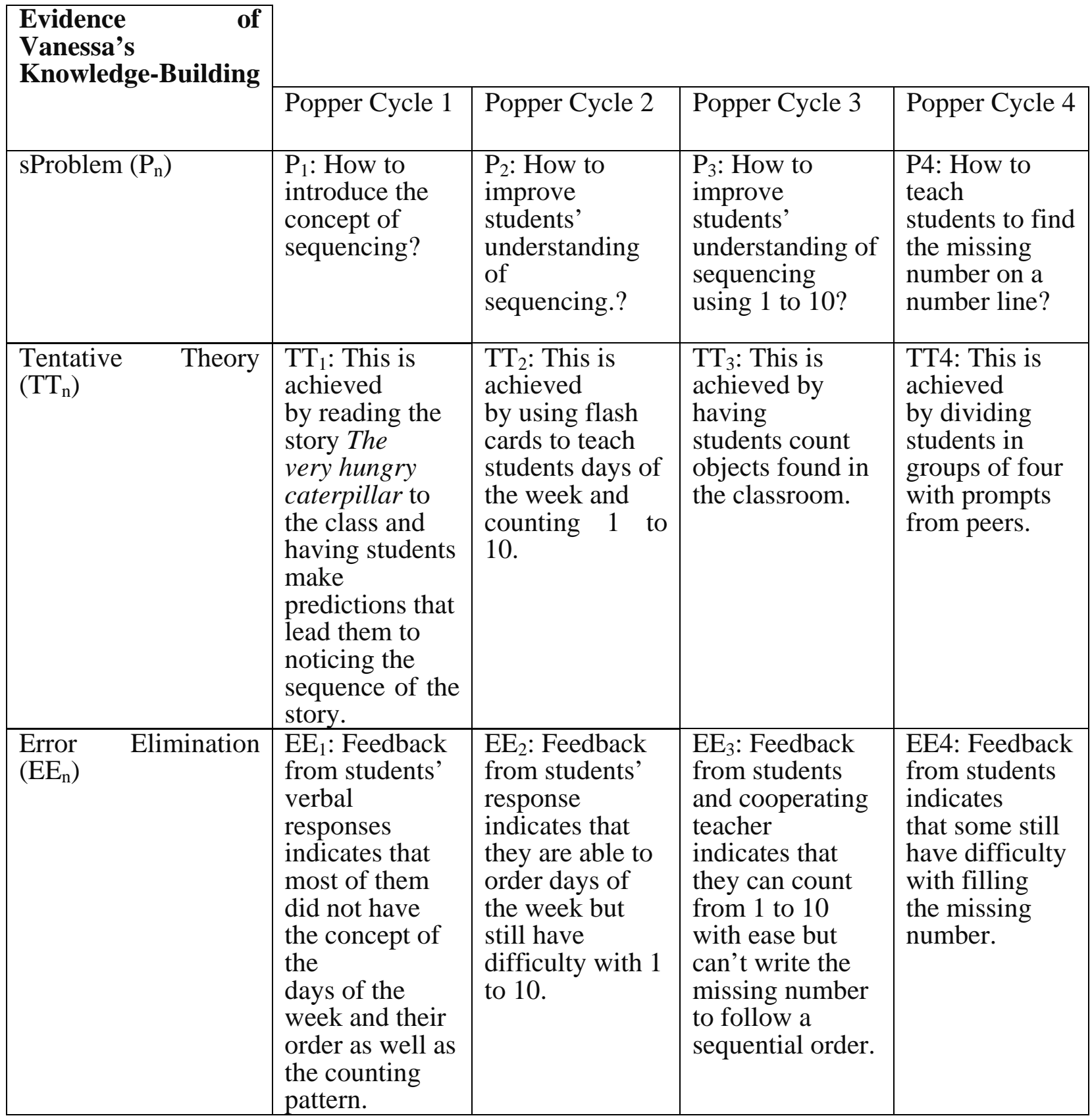

From Chitpin et and Simon. (2006) 